\title{
Incidence of thrombocytopenia following phototherapy in hyperbilirubinemic neonates
}

\author{
Maj Sanjeev Khera*, Col Rakesh Gupta ${ }^{\dagger}$
}

\section{ABSTRACT}

\section{BACKGROUND}

Thrombocytopenia has not been conclusively reported as a complication of phototherapy in any of the standard paediatric textbooks.

\section{MATERIALS AND METHOD}

A prospective study in consecutively enrolled cohort of apparently healthy neonates, who developed indirect hyperbilirubinaemia and required phototherapy. Neonates having a base line platelet count of more than $150,000 / \mathrm{mm}^{3}$ were included. Neonates having features suggestive of haemolysis, direct hyperbilirubinaemia, sepsis, anti-platelet drugs given to baby or mother, haemangioma, and other congenital anomalies were excluded. Platelet counts were performed at admission, 24 hours, 48 hours, and before discontinuing phototherapy.

\section{RESULTS}

Out of 100 neonates included in study 35 (35\%) had thrombocytopenia and a majority of neonates had mild thrombocytopenia (74\%). The thrombocytopenia was seen in 26 (74\%) cases during the first 24 hours of phototherapy and usually was not associated with clinical bleed.

\section{CONCLUSION}

This study establishes an association of phototherapy as a cause of thrombocytopenia in hyperbilirubinaemic neonates. Though the incidence of thrombocytopenia is substantial yet it is clinically insignificant. This study helps the practitioner to be aware of this association and avoid unnecessary investigations, as thrombocytopenia was transient.

MJAFI 2011;67:329-332

Key Words: indirect hyperbilirubinaemia; neonatal thrombocytopenia; phototherapy

\section{INTRODUCTION}

Neonatal jaundice is a common problem, and in most cases being physiological does not require active intervention. Jaundice

*Graded Specialist (Paediatrics), Military Hospital, Danapur, C/o 56 APO, ${ }^{\dagger}$ Associate Professor, Department of Paediatrics, AFMC, Pune - 40.

Correspondence: Maj Sanjeev Khera, Graded Specialist, Military Hospital, Danapur, C/o 56 APO.E-mail: kherakherakhera@gmail.com

Received: 28.07.2010; Accepted: 19.08.2011

doi: 10.1016/S0377-1237(11)60078-6 is observed in first week of life in approximately $60 \%$ full-term and $80 \%$ pre-term neonates. ${ }^{1,2}$ The various modalities of treatment for neonatal jaundice include phototherapy, exchange transfusion, and drugs like phenobarbitone, intravenous immunoglobulin, metalloporphyrin, etc. Amongst them, phototherapy has emerged as the most widely used form for the treatment of unconjugated hyperbilirubinaemia. It reduces or blunts the rise of unconjugated bilirubin levels regardless of maturity, presence or absence of haemolysis. ${ }^{3,4}$

Phototherapy though safe, is not free of side effects. Neonates receiving phototherapy have increased insensible water loss, redistribution of blood flow, watery diarrhoea, irritability, rise in temperature, retinal damage, bronze baby syndrome, gonadal toxicity, impaired maternal-infant interaction, hypocalcaemia, riboflavin deficiency, DNA strand breakage, chromosomal mutations damage, and in few studies even thrombocytopenia. ${ }^{1,2,5,7}$

Thrombocytopenia as a side effect of phototherapy that has not been described in the standard textbooks although many authors did try to look into this particular side effect. Maurer et $\mathrm{al}^{5,6}$ and Pishwa et $\mathrm{al}^{7}$ observed in their studies that neonates exposed to phototherapy had decreased platelet counts and increased platelet turnover.

This study was done with an aim to find the incidence of thrombocytopenia in neonates with indirect hyperbilirubinaemia receiving phototherapy.

\section{MATERIALS AND METHOD}

This was a prospective study done at a tertiary care hospital between July 2007 and July 2009; in consecutively enrolled cohort of apparently healthy neonates, who developed indirect hyperbilirubinaemia and required phototherapy irrespective of gestational age and birth weight. The indication of phototherapy was based on the guidelines of American Academy of Pediatrics $2004 .^{8}$ The neonates having a base line platelet count of more than $150,000 / \mathrm{mm}^{3}$ before starting phototherapy were included in the study. Neonates having features suggestive of haemolysis, direct hyperbilirubinaemia, sepsis, anti-platelet drugs given to baby or mother, haemangioma, and other congenital anomalies were excluded. Neonates who developed features suggestive of sepsis during phototherapy were also excluded.

Neonates who fulfilled the inclusion criteria were admitted to the hospital. After a detailed history, clinical examination and baseline investigations all babies were put on continuous phototherapy. Platelet counts were performed at admission, 24 hours, 
48 hours, and before discontinuing phototherapy; by automated haematology analyzer KX 21 and reconfirmed by microscopy.

Thrombocytopenia was defined as platelet count $<150,000 /$ $\mathrm{mm}^{3}$. Mild, moderate and severe thrombocytopenia were defined as platelet counts between $100,000-150,000 / \mathrm{mm}^{3} ; 50,000-$ $100,000 / \mathrm{mm}^{3} ;<50,000 / \mathrm{mm}^{3}$, respectively. Neonates showing a fall of platelet count were recorded.

Neonates were then divided in two groups namely group A and group B showing the presence and absence of thrombocytopenia, respectively. Various factors like levels of serum bilirubin at the onset of phototherapy and subsequently, on days 1 and 2, duration as well as the type of phototherapy and epidemiological factors such as sex, birth weight, gestational age, neonatal age; maternal factors like maternal age and parity were studied and compared in the two groups.

Data analysis was done by using ' $\chi^{2}$ corrected (Yates) test' for proportions (qualitative variables) or an 'unpaired $t$-test' for means (quantitative variables). A logistic regression analysis was done to look for epidemiological factors and phototherapyrelated factors as potential confounders. $P<0.05$ was taken as significant. All the statistical analysis was done using 'Epi-info' 3.4.3 version software.

\section{RESULTS}

A total of 102 neonates were enrolled in the study. Two neonates were excluded. Both had features of haemolysis and direct Coombs test (DCT, also known as direct antiglobulin) positivity. A total of 100 newborns were evaluated in the study. All of them either had physiological jaundice or the cause was not clear. The incidence of thrombocytopenia was seen in 35 (35\%) neonates undergoing phototherapy (Figure 1). Majority of neonates had mild thrombocytopenia (74\%). Moderate and severe thrombocytopenia was seen in $23 \%$ and $3 \%$ cases, respectively (Figure 2).

\section{Epidemiological Characteristics}

Of the total 100 neonates under study, there were 64 males and 36 were females. Twenty-five neonates were having weight $<2,500 \mathrm{~g}, 18$ neonates were pre-term, and 82 were full-term neonates. Fifty-five of the neonates were born to primiparous mothers and 45 to multipara. Onset of jaundice was between 2 and 8 days postnatal age. The epidemiological characteristics in the two groups are as shown in Table 1.

There was no statistically significant difference in the incidence of thrombocytopenia based on sex (male $71 \%$ vs female $29 \%$ ), gestational age (pre-term $14 \%$ vs full-term $86 \%$ ), birth weight (low birth weight, 9\% vs anti-gladin antibodies, 91\%), maternal parity and age of onset of jaundice.

\section{Thrombocytopenia and Phototherapy}

The thrombocytopenia was seen in 26 (74\%) cases during the first 24 hours of phototherapy. There was a steady decline in the mean platelet count in the initial 48-72 hours after administration of phototherapy, thereafter because of cessation of

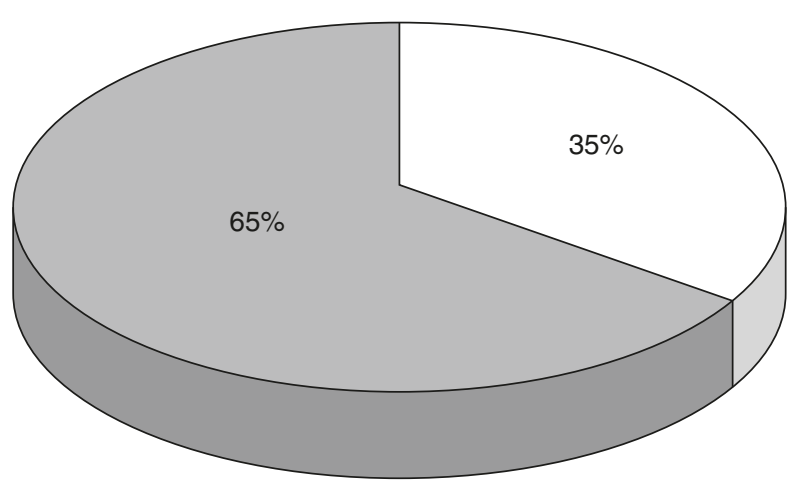

$\square$ Thrombocytopenia $\square$ Non-thrombocytopenia

Figure 1 Incidence of thrombocytopenia.

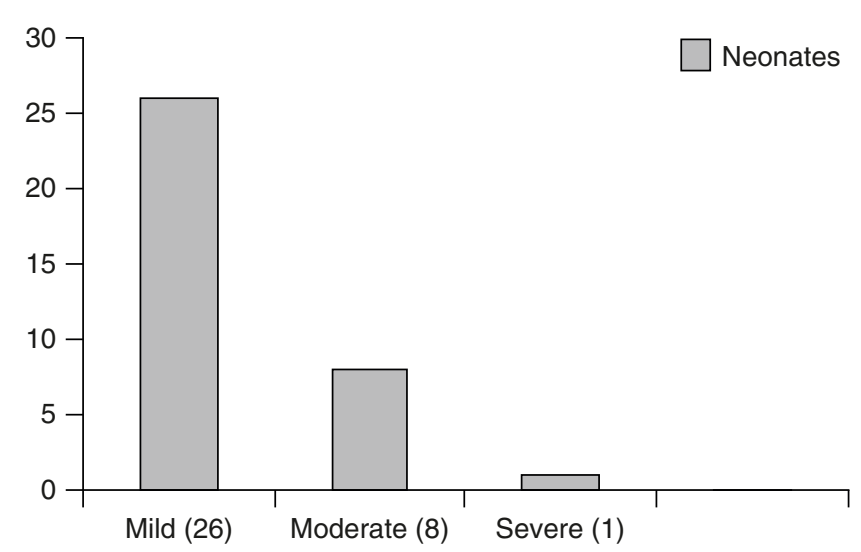

Figure 2 Severity of thrombocytopenia.

phototherapy in most of the cases there was a slow rise in the platelet count (Figure 3).

Double surface phototherapy (DSPT) causes thrombocytopenia in more neonates compared to single surface phototherapy. Duration of phototherapy more than 48 hours was associated with more cases of low platelet as compared to shorter duration and fall was maximum when serum bilirubin levels was $>18 \mathrm{mg} / \mathrm{dL}$. But the associations between the two groups were not statistically significant $(P>0.05)$ (Table 2$)$.

The mean initial platelet count in thrombocytopenic group was lower $\left(189,885 / \mathrm{mm}^{3}\right)$ compared to the non-thrombocytopenic group $\left(246,430 / \mathrm{mm}^{3}\right)$. Minimum platelet count in our study was $33,000 / \mathrm{mm}^{3}$; however, none of the neonates had bleeding symptoms.

A logistic regression analysis done to look for epidemiological factors and phototherapy-related factors as potential confounders showed no significant association.

\section{DISCUSSION}

In our study, the incidence of thrombocytopenia after 48 hours of phototherapy was $35 \%$. In a similar study by Maurer et $\mathrm{al}^{5}$ 
Table 1 The comparison of epidemiological characteristics in two groups.

\begin{tabular}{|c|c|c|c|c|c|}
\hline S. no. & Characteristics & $\begin{array}{l}\text { With thrombocytopenia } \\
\quad \text { (group A, } n=35 \text { ) }\end{array}$ & $\begin{array}{l}\text { Without thrombocytopenia } \\
\quad \text { (group B, } n=65 \text { ) }\end{array}$ & $\begin{array}{c}\text { Total } \\
n=100\end{array}$ & $P$ value \\
\hline \multirow[t]{3}{*}{1} & Sex & & & & 0.35 \\
\hline & Male & 25 & 39 & 64 & \\
\hline & Female & 10 & 26 & 36 & \\
\hline \multirow[t]{3}{*}{2} & Birth weight (g) & & & & 0.11 \\
\hline & $<2,500$ & 5 & 20 & 25 & \\
\hline & $\geq 2,500$ & 30 & 45 & 75 & \\
\hline \multirow[t]{3}{*}{3} & Period of gestation (wk) & & & & 0.12 \\
\hline & $<37$ & 3 & 15 & 18 & \\
\hline & $\geq 37$ & 32 & 50 & 82 & \\
\hline \multirow[t]{4}{*}{4} & Neonatal age of onset of jaundice (d) & & & & 0.54 \\
\hline & $>2-3$ & 13 & 29 & 42 & \\
\hline & $>4-5$ & 15 & 28 & 43 & \\
\hline & $>6$ & 7 & 8 & 15 & \\
\hline \multirow[t]{3}{*}{5} & Parity of mother & & & & 0.11 \\
\hline & Primipara & 15 & 40 & 55 & \\
\hline & Multipara & 20 & 25 & 45 & \\
\hline
\end{tabular}

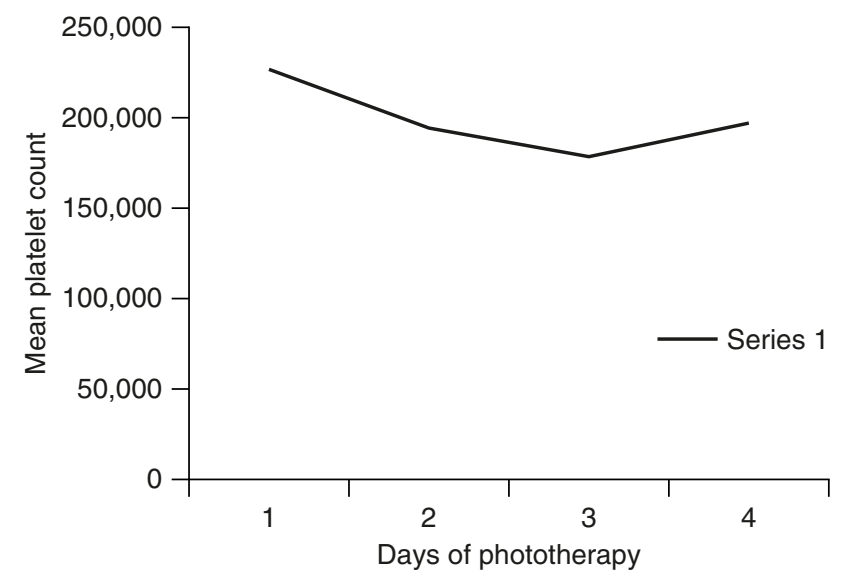

Figure 3 Mean platelet count and duration of phototherapy.

in low birth weight infants, the effect of 96 hours of continuous daylight phototherapy on platelets showed that $38.7 \%$ of babies had thrombocytopenia and Pishwa et $\mathrm{al}^{7}$ observed similar findings in $49 \%$ neonates. ${ }^{7}$ The thrombocytopenia was seen in maximum number of cases during the first 24 hours of phototherapy. Similar findings were noted in study by Maurer et al. ${ }^{5}$

In our study, the average initial platelet count in thrombocytopenia group was $189,885 / \mathrm{mm}^{3}$, while the average initial platelet count in non-thrombocytopenia group was $246,430 / \mathrm{mm}^{3}$ suggesting a pre-existing borderline marrow reserve. Full-term neonates with normal birth weight unexpectedly had lower platelet counts as compared to pre-term and low birth weight in our study and this could not be explained; however, similar facts were also observed by Maurer et al. ${ }^{5}$

Thrombocytopenia was seen more with male sex, normal birth weight, term, higher age of onset of jaundice, multiparous mother, and DSPT given for more than 48 hours; however, these associations were not statistically significant. Similar observations were seen by Pishwa et $\mathrm{al}^{7}$ in their study. We have not included control group in our study since the neonate with platelet count $<150,000 / \mathrm{mm}^{3}$ were excluded from the study. None of the neonates with thrombocytopenia, in our as well as the other two studies, had clinical manifestations of bleeding. The reason for the same could be the fact that thrombocytopenia was transient and rarely found to be severe in all the three studies.

The steady decline in the mean platelet count in the initial 48-72 hours after administration of phototherapy followed by slow rise after cessation of phototherapy; and association of phototherapy more than 48 hours with more cases of low platelet as compared to shorter duration, may imply that the fall in platelet count was dose- and duration-dependent.

Thrombocytopenia as a definite side effect of phototherapy has not been mentioned in the standard text books and only described briefly as isolated case reports after the phototherapy came in vogue since 1958 . In 1966, Zieve et al $^{9}$ demonstrated effects of high intensity white light on human platelet in vitro. Platelets which had been briefly exposed to light following photosensitization by hematoporphyrin lost the ability to aggregate and release potassium, acid phosphatase, serotonin and adenosine triphosphate. Electron photomicrographs of these altered platelets showed depletion of cytoplasmic materials and smooth membrane contours as compared to controls. Maurer et $\mathrm{al}^{5}$ observed similar kind of platelet abnormalities within 96 hours of exposure in vivo.

Ultraviolet light may increase platelet turnover and injury during phototherapy by an unknown mechanism. Phototherapy light is transmitted through living tissue to a degree which may lead to photochemical reactions to occur in the vascular bed. ${ }^{10}$ 
Table 2 The comparison of serum bilirubin levels, duration and dose of phototherapy between the two groups.

\begin{tabular}{|c|c|c|c|c|c|}
\hline S. no. & Characteristics & $\begin{array}{l}\text { With thrombocytopenia } \\
\quad \text { (group A, } n=35 \text { ) }\end{array}$ & $\begin{array}{l}\text { Without thrombocytopenia } \\
\quad \text { (group B, } n=65 \text { ) }\end{array}$ & $\begin{array}{c}\text { Total } \\
n=100\end{array}$ & $P$ value \\
\hline \multirow[t]{3}{*}{1} & Dose of phototherapy & & & & 0.65 \\
\hline & DSPT & 18 & 29 & 47 & \\
\hline & SSPT & 17 & 36 & 53 & \\
\hline \multirow[t]{3}{*}{2} & Duration of phototherapy (hr) & & & & 0.44 \\
\hline & $\leq 48$ & 18 & 40 & 58 & \\
\hline & $>48$ & 17 & 25 & 42 & \\
\hline \multirow[t]{3}{*}{3} & Serum bilirubin (mg/dL) & & & & 0.11 \\
\hline & $\leq 18$ & 28 & 59 & 87 & \\
\hline & $>18$ & 7 & 6 & 13 & \\
\hline
\end{tabular}

It causes decrease in blood riboflavin level and alters the excretory pattern of tryptophan metabolites, both of which are photosensitive. ${ }^{11}$ The phototherapy causes an increase in platelet production rate possibly secondary to reduction in platelet life span and when bone marrow compensation is inadequate the platelet count may fall. ${ }^{5}$ The in vitro data suggest that photochemical reactions occur in the platelet membrane. Whether these reactions occur in vivo remains to be determined. Shortened platelet life span may be the result of sequestration of damaged platelets in the spleen; however, definite proof is lacking.

The strengths of the study were that this was a consecutively enrolled prospective cohort study. The indication as well as the methodology of subjecting a neonate to phototherapy was as per the standard guidelines. Sample size was also substantial and caters for adequate power of study. Well-defined exposure variable and inclusion criteria, study of single outcome variable, i.e. thrombocytopenia which was again well-defined and doubly checked by automated counter, and experienced pathologists make this study a simple but effective one.

Single centre study, inability to quantify flux of phototherapy, and inability to delineate the cause of hyperbilirubinaemia in the neonates studied could be the weaknesses of the study.

\section{CONCLUSION}

To conclude, this study establishes an association of phototherapy as a cause of thrombocytopenia in hyperbilirubinaemic neonates. Though the incidence of thrombocytopenia is substantial, yet it is clinically insignificant. This study helps the practitioner to be aware of this association and avoid unnecessary investigations, as thrombocytopenia was transient.

\section{Intellectual Contributions of Authors}

Study concept: Maj Sanjeev Khera

Drafting and manuscript revision: Col Rakesh Gupta

Statistical analysis: Maj Sanjeev Khera

Study supervision: Col Rakesh Gupta

\section{CONFLICTS OF INTEREST}

None identified.

\section{REFERENCES}

1. Plazza A, Stoll B. The fetus and the neonatal infant. Digestive system disorders. In: Nelson Textbook of Pediatrics 18th ed. Kliegman R, Behrman R, Jenson H, Stanton B, eds. Philadelphia: Saunders Elsevier, 2007:756-761.

2. Martin CR, Cloherty JP. Neonatal hyperbilirubinemia. In: Manual of Neonatal Care 6th ed. Cloherty JP, Eichenwald EC, Stark AR, eds. Philadelphia: Lippincott Williams \& Wilkins, 2008:181-212.

3. Lucey J, Ferriero M, Hewitt J. Prevention of hyperbilirubinemia of prematurity by phototherapy. Pediatrics 1968;41:1047-1054.

4. Maisels MJ. Jaundice. In: Neonatology: Pathophysiology and Management of the Newborn 4th ed. Avery GB, Fletcher MA, MacDonald MG, eds. Philadelphia: Lippincott-Raven Pubs, 1994:630-708.

5. Maurer HM, Fratkin M, McWilliams NB, et al. Effects of phototherapy on platelet counts in low-birthweight infants and on platelet production and life span in rabbits. Pediatrics 1976;57:506-512.

6. Maurer HM, Haggins JC, Still WJ. Platelet injury during phototherapy. Am J Hematol 1976;1:89-96.

7. Pishva N, Pishva H. Incidence of thrombocytopenia in hyperbilirubinemic neonates during phototherapy. Acta Medica Iranica 2000; 38:7-9.

8. American Academy of Pediatrics Subcommittee on Hyperbilirubinemia. Management of hyperbilirubinemia in the newborn infant 35 or more weeks of gestation. Pediatrics 2004;114:297-316. Erratum in: Pediatrics 2004;114:1138.

9. Zieve PD, Solomon HM, Krevans JR. The effect of hematoporphyrin and light on human platelets. I. Morphologic, functional, and biochemical changes. J Cell Physiol 1966;67:271-279.

10. Sisson TRC, Wickler M. Transmission of light through living tissue. Pediatr Res 1973;7:316.

11. Rubaltelli FF, Allegri G, Costa C, De Antoni A. Urinary excretion of tryptophan metabolites during phototherapy. J Pediatr 1974;85:865-867. 